\title{
Tradução e Ética: Sobre ética da tradução como uma prática social de reflexão consciente
}

\author{
Daniel Antonio de Sousa Alves ${ }^{1}$ \\ Universidade Federal da Paraíba - UFPB, João Pessoa, Paraíba, Brasil
}

Resumo: Traduções são resultados de complexos processos de escolha, que envolvem desde as possibilidades de interpretação abertas pelos textos-fonte, até as possibilidades de construção textual oferecidas pelo sistema da língua-alvo, incluindo, entre outros fatores, as restrições externas colocadas por agentes envolvidos no processo de tradução. Este texto se ampara em Singer (2011) para abordar a ética tradutória como uma prática social que promove a reflexão consciente sobre os comportamentos sociais do indivíduo e estimula a construção e a publicação de projetos tradutórios, apoiando-se em Berman (1995), Simon (1996) e Kremer (2007). Abordam-se aqui questões relativas à construção de projetos de tradução e tomada de decisões de tradução e à forma como escolhas tradutórias podem ser reveladoras acerca dos processos individuais de interpretação de textos e dos sistemas linguísticos nos quais eles se inserem.

Palavras-chave: Estudos da Tradução; Tradução e ética; Projetos tradutórios.

Title: Translation and Ethics: On Ethics as a social practice of conscious reflection

Abstract: Translated texts result from complex decision-making processes that encompass the from possibilities of interpretation provided by the source text, to the possibilities of textual construal limited by the target system, including, among other factors, the external restrictions imposed by stakeholders invested in the process. This paper draws on Singer (2001) to approach translation ethics as a social practice that promotes a conscious reflection on the social behavior of the individual and fosters the construal and the publication of translation projects, following Berman (1995), Simon (1996) and Kremer (2007). The paper addresses matters of formulation of translation projects, of text construal and of the manner in which translation choices can be revealing in terms of how translators interpret texts and understand the linguistic systems with which they work.

Keywords: Translation Studies; Translation and Ethics; Translation Projects.

That isn't ethics. Ethics is a real discussion of the competing

conceptions of the good. This is just the corporate anti-shoplifting

rules.

\footnotetext{
${ }^{1}$ Doutor em Estudos da Tradução pela UFSC. Professor adjunto do curso de Bacharelado em Tradução da Universidade Federal da Paraíba (UFPB). Orcid: https://orcid.org/0000-0002-3702-0895 E-mail: daniel@cchla.ufpb.br
} 


\section{Introdução}

A epígrafe escolhida para enquadrar esta reflexão teórica foi retirada do terceiro episódio da quinta temporada da comédia televisiva The Office (US), intitulada em inglês "Business Ethics". Na epígrafe, é mostrada uma fala do personagem Oscar que, durante um seminário sobre ética no meio corporativo, protesta ao ser deparado com uma visão restrita de ética como um sistema de regras fechadas. Em seu protesto, o personagem tenta elevar a discussão, chamando atenção para a existência de diferentes concepções sobre o que constitui a noção de correto e para a complexidade em torno desse debate.

Este texto buscará promover uma discussão teórica sobre ética, trazendo-a para o contexto dos Estudos da Tradução e tentando evitar o estabelecimento de regras fechadas descrito no parágrafo anterior (não assumindo, portanto, a postura deôntica), mas adotando uma postura relativista que reflete sobre como um mesmo objeto pode ser observado a partir de visões concorrentes. Na busca por essa reflexão, este texto debaterá sobre como o processo de construção de significados a partir de um texto-fonte necessariamente abre múltiplas possibilidades de interpretação e sobre como essas interpretações podem abrir (também múltiplas) possibilidades para a formulação de projetos tradutórios - aqui entendidos como os sistemas subjacentes às escolhas tradutórias que levam à construção de qualquer texto-alvo.

É necessário reconhecer, no entanto, que mesmo uma discussão relativista, como a aqui proposta, tem suas limitações. Contextos mais influenciados por pressões de mercado, como o de editoras comerciais, por exemplo, tendem a ser menos receptivos a discussões que não levem a uma aceleração nos processos de tomadas de decisões - o que talvez seja uma razão por trás da existência de diversos materiais sobre ética e tradução que adotam um viés deôntico ${ }^{2}$ e que tendem a limitar o leque de fatores a serem considerados nas discussões sobre o tema. Ambientes acadêmicos, por outro lado, tendem a ser mais abertos a discussões que privilegiam a reflexão e o debate, reconhecendo a multiplicidade de fatores que pode influenciar um determinado objeto ou processo. A partir desse contraste de contextos, este trabalho reconhece, de antemão, os diferentes locais para a promoção de diferentes debates e não se propõe a avançar sobre contextos em que uma lógica deôntica possa ser mais aplicável. Ao se localizar dessa forma, este texto busca inserção em contextos nos quais há espaço para discussões sobre como um mesmo texto-fonte pode levar à

${ }^{2}$ Cito, como exemplos de códigos de ética com vieses deônticos:

- TRANSLATOR CODE OF ETHICS: High Quality Translation and Interpretation Services Disponível em https://multi-languages.com/translations-shtml/translators ethics-shtml/ último acesso em 11/11/2020.

- American Translators Association Code of Ethics and Professional Practice - Disponível em https://www.atanet.org/governance/code of ethics.php - último acesso em 11/11/2020.

- Código de ética do interprete de libras - Disponível em http://escolainterlibras.com.br/codigo-de-etica-do-interprete-de-libras/ - último acesso em $11 / 11 / 2020$. 
construção de diferentes interpretações, com diferentes nuances e diferentes possibilidades de tradução.

Para atingir seus objetivos, este texto está organizado em quatro seções, contando com esta introdução; a saber: i) Considerações sobre ética, na qual são discutidos conceitos iniciais e feitas considerações sobre ética inserida em um contexto dos Estudos da Tradução; ii) Ética da tradução e projetos tradutórios, na qual são apresentadas reflexões sobre políticas tradutórias e suas construções e sobre a importância delas para a construção de textos-alvo; por fim, iii) Considerações finais, na qual são retomadas possíveis leituras e feitas considerações sobre outras discussões acerca do tema ética. Essa última seção também reconhece a existência de outras abordagens sobre ética no contexto dos Estudos da Tradução e faz indicações de outros trabalhos que apontam caminhos para discussões diferentes da aqui desenvolvida.

\section{Considerações sobre ética}

Ao longo de todo o livro, Singer (2011) ressalta a característica de a ética de ser, por si só, um tema abrangente, com várias ramificações e implicações filosóficas, apontando não haver consensos sobre o que é ética, sobre o que não é ética, tampouco sobre a própria existência de uma dicotomia entre o ético e o não-ético. O autor pontua que a simples definição de o que constitui ética é alvo de diferentes percepções e muitas vezes é confundida com um debate sobre a defesa da moralidade, às vezes permeado por discursos religiosos. Para os fins deste trabalho - que não se propõe a uma discussão sobre ética pura e não faz, portanto, uma revisão abrangente das mais diferentes concepções sobre ética - , será adotada a definição de Singer (2011, p.284-5) de ética como uma prática social que visa a promover a reflexão consciente sobre os comportamentos e os interesses de indivíduos em relação aos seus grupos sociais e às expectativas sociais desse grupo.

Nessa visão promovida por Singer (2011, p.285), a reflexão sobre os motivos que levam um comportamento a ser considerado como desejável (ou não desejável) em um dado contexto social passa a ter relevância equiparável à do próprio comportamento sob escrutínio. Para o autor, simplificar ética a uma mera visão de 'o que é correto', sem a devida análise dos motivos subjacentes - tanto daqueles por trás tanto do próprio comportamento, quanto daqueles por trás dos valores sociais que levam tal comportamento a ser considerado correto - pode levar a situações de negação da capacidade do indivíduo em avaliar seu contexto social e seu raio individual de ação.

Singer (2011, p.270) faz tal defesa da ética como uma prática social que preza pela reflexão consciente se amparando na ideia de que não há absolutos (tampouco uma divisão estanque) em uma discussão entre o correto e o errado, muitas vezes cabendo ao indivíduo a decisão de como agir frente a uma situação concreta. Em sua argumentação, o autor aponta que, embora haja uma expectativa idealizada de uma confluência entre a) o que uma sociedade valoriza como positivo; b) o que a lei dessa sociedade preconiza como 
comportamento desejável; e c) o que um indivíduo que faz parte dessa sociedade decide fazer frente a uma dada situação, a relação entre essas três variáveis nem sempre é pacífica - o que reforça a importância da discussão consciente acerca do contexto da ação do indivíduo.

Nessa argumentação, Singer (2011) apoia-se em Henry David Thoreau ${ }^{3}$ e em Robert Paul Wolff ${ }^{4}$ para discutir os conflitos resultantes de situações em que os três fatores mencionados no parágrafo anterior não confluem segundo essa expectativa idealizada (ou mesmo em que tal há uma grande divergência entre os três). Discussões sobre desobediência civil e resistência pacífica trazem bons exemplos ${ }^{5}$, nos mais diferentes âmbitos, que podem ser usados para justificar a importância de se privilegiar a reflexão consciente sobre ações e comportamentos dos indivíduos em suas sociedades, em detrimento de uma simples colocação de 'o que é correto'.

Em se tratando de uma discussão de ética em um contexto dos Estudos da Tradução, igualmente se pode valorizar a reflexão consciente em detrimento de uma colocação absoluta de 'o que é uma boa tradução', também se levando em consideração que há muitos fatores e perspectivas envolvidos. Um fator a ser aqui destacado é o papel desempenhado pelo(a) próprio(a) leitor(a) na construção do texto-fonte e as implicações disso para a construção de textos-alvo. Segundo Bassnett (1980), um dos grandes avanços dos estudos literários no século XX é a mudança no paradigma do(a) leitor(a), que deixa de ser um(a) consumidor(a) passivo(a) dos textos e passa a ser visto(a) como sujeito ativo(a) no processo de comunicação, chegando a ter status de coprodutor(a) do texto.

Com essa mudança de paradigma, ainda de acordo com Bassnett (1980), os estudos literários deixam de lado a ideia de que um texto tem uma leitura única, correta e invariável e passam a abraçar as diferentes possibilidades de interpretação que decorrem da ação dos(as) diferentes leitores(as). Essa propriedade das narrativas literárias também é ressaltada por Fludernik (1996), que discute como textos permitem que leitoras e leitores ativamente construam significados, fazendo associações e interpretações relacionadas aos seus esquemas individuais de percepção da realidade.

A discussão sobre o papel do(a) leitor(a) na construção do texto não se limita à literatura. Costa Val (2004) abordando as noções texto, textualidade e textualização baseando-se na linguística textual de Beaugrande e Dressler $(1981)^{6}-$ também ressalta que

3 O ensaio de Thoreau sobre resistência ao governo civil, comumente chamado de "Civil Disobedience" foi originalmente publicado em 1849 e se encontra, atualmente, em domínio público.

${ }^{4}$ WOLFF, Robert Paul. In Defense of Anarchism. London: University of California Press, (1998).

${ }^{5}$ Tais exemplos não são aqui explicitados devido ao escopo deste texto. Para mais informações sobre os conflitos mencionados no parágrafo, recomendo a leitura de Singer (2011, p. 256-9), em que o autor discute a) exemplos de ações ilegais em contextos de normas moralmente questionáveis; $b$ ) exemplos de ações legais, mas realizadas em contextos de ineficiência institucional; c) exemplos de ações ilegais, amparadas em alegações de valores morais. Nessa discussão, o autor aborda a complexidade das relações estabelecidas entre as ações do indivíduo, as expectativas de sua sociedade e as normas que regem essa sociedade.

${ }^{6}$ BEAUGRANDE, Robert-Alain e DRESSLER, Wolfgang. Introduction to Text Linguistics. London, Longman, 1981. 
o significado não é algo imanente ao texto, mas construído por meio de um processo dialógico e interativo. A autora trabalha com uma definição de textualidade como "um princípio geral que faz parte do conhecimento textual dos falantes e que os leva a aplicar a todas as produções lingüísticas que falam, escrevem, ouvem ou lêem um conjunto de fatores capazes de textualizar essas produções" (COSTA VAL, 2004, p.114 - grifo da autora). Emblemática dessa mudança de postura em relação à construção de significados é a fala da autora ao introduzir os conceitos de coesão e coerência

\begin{abstract}
Os conceitos de coerência e coesão foram usados por muita gente, inclusive eu, no livro Redação e Textualidade, como definidores de qualidades que um determinado texto tinha ou deixava de ter. Se pudesse reescrever meu livro, que foi publicado em 1991, eu hoje modificaria a maneira como tratei dessas questões. Não diria mais que a redação $A$ tem coerência e que a redação $B$ não tem; nem que a redação $C$ tem coesão e a redação $D$ não tem. Diria que eu, na posição de leitora, pude textualizar aquelas redações da maneira $X$ ou $Y$, e que foi fácil para mim produzir coerência e coesão para as redações $A$ e $C$, mas foi difícil fazer o mesmo quanto às redações B e D. (COSTA VAL, 2004, p.114 - grifos da autora).
\end{abstract}

Na citação acima, é possível notar como a Costa Val (2004) reforça explicitamente sua mudança de postura, ao apontar como deixa de ver coesão e coerência como propriedades imanentes de um texto e passa a ver o texto como uma construção que, necessariamente, envolve a participação ativa do(a) próprio(a) leitor(a).

Além da visão do(a) leitor(a) como coprodutor(a) ativo(a) do texto, outro fator a ser levado em consideração é a própria existência (ou não) de uma realidade objetiva. Autores(as), como Nietzche (1901), por exemplo, discutem como aquilo que classificamos como realidade é fruto de uma interpretação, moldada por uma perspectiva. Nietzche (1901) ressalta a impossibilidade da existência de uma verdade absoluta (ou de fatos que existam por si próprios) e aponta a perspectiva e a interpretação - associadas aos interesses pessoais do indivíduo - como cernes das percepções humanas acerca da realidade. 0 perspectivismo de Nietzche implica a aceitação da multiplicidade de interpretações como pressuposto da realidade e convida à reflexão sobre o papel da pessoa que interpreta a realidade e sobre suas eventuais agendas (já que, para o autor, a interpretação também é uma forma de estrutura de poder) acerca de todas as coisas que percebemos como reais.

Trazendo esse perspectivismo para o contexto dos Estudos da Tradução, admitir que um mesmo texto-fonte abre múltiplas possibilidades de leitura igualmente válidas, implica aceitar que cada texto-fonte pode abrir espaço para múltiplas possibilidades de tradução, também igualmente válidas. Além disso, entender a interpretação como uma ação associada às agendas do indivíduo, pode ser vista como um convite para a compreensão e para a discussão crítica sobre as motivações subjacentes à tradução como uma ação social.

Para Bassnett (1980), uma consequência, para o campo disciplinar, de se aceitar a multiplicidade de significados como algo inerente a qualquer texto é a diminuição da importância das tentativas de categorização "entre traduções, versões, adaptações e [d]o estabelecimento de uma hierarquia de 'correção entre essas categorias'" (BASSNETT, 1980, 
p.84). Para a autora, a diferenciação entre as categorias citadas deriva, em primeiro lugar, da noção de leitor(a) como sujeito passivo e, em segundo lugar, da noção de significado como propriedade imanente do texto e não como um produto do dialogismo intrínseco ao processo de leitura e produção de significados.

Dando sequência às discussões sobre fatores a serem considerados em uma discussão sobre ética vista no contexto dos Estudos da Tradução, este texto passa a se concentrar na construção de textos-alvo a partir de projetos tradutórios, ainda evitando o maniqueísmo de certo versus errado e evitando o estabelecimento de hierarquias de correção ou de avaliação de traduções (em termos qualitativos). Trata-se aqui de uma tentativa de reforçar a discussão sobre a possibilidade de inúmeras leituras e de construções tradutórias a partir disso, mas reconhecendo que uma escolha de tradução (feita em detrimento de outra) pode abrir espaço para diferentes construções de textos-alvo. A próxima seção parte desse dialogismo implícito a leituras de textos (e também à produção de traduções) para abordar a construção de projetos tradutórios e seu papel construção dos textos-alvo.

\section{Ética da tradução e projetos tradutórios}

Pressupor que textos-fonte abrem múltiplas possibilidades de interpretação e, consequentemente, podem ser traduzidos de diferentes formas, também tem como consequência a necessidade de se promover uma visão da ética da tradução que supere aquilo que Kremer (2007) chama de ética da igualdade. Kremer (2007) - que classifica essa ética da igualdade como uma postura ilusionista que tenta se impor como absoluta e universal - critica a noção equivocada de que a atividade do(a) tradutor(a) pode ser isenta e apagada de motivações políticas ${ }^{7}$, além de criticar a expectativa de que traduções sejam meras reproduções de textos originais, que, por sua vez, são vistos como sacralizados e imutáveis no tempo. Essa ética da igualdade, associada à condição de invisibilidade de tradutores e tradutoras, gera, segundo $\operatorname{Kremer}(2007$, p.4004), um contexto propício para a realização de interferências veladas pois "[cria-se] no leitor a expectativa de estar lendo o texto "original" sem mediações, quando de fato, [o tradutor] está manipulando o texto sem assumir sua interferência".

Kremer (2007), tanto em sua discussão teórica quanto no estudo de caso que promove - ao analisar o caso de uma tradução de Dom Casmurro para a língua inglesa que ignora grandes passagens do texto-fonte, excluindo capítulos sem que sejam feitas quaisquer ressalvas ou anúncios, informando essa decisão ao público-alvo - , ressalta a necessidade de reconhecer que toda tradução, por mais despretensiosa que possa parecer, é uma forma de

\footnotetext{
${ }^{7}$ Neste texto, utilizo a palavra 'política' em seu sentido mais amplo, entendendo-a como referência às atividades humanas, individuais ou coletivas, realizadas em função de agendas e interesses, e localizadas em suas sociedades. Nos usos da palavra neste texto, não há intenção de fazer qualquer alusão a política partidária ou a política como forma de poder organizado.
} 
intervenção política, na qual o(a) tradutor(a) se coloca como agente, consciente ou não, da promoção de ideias que ocorre em qualquer contato entre línguas e culturas. Mais do que simplesmente reescrever textos de uma língua $A$ em uma língua $B$, tradutores têm um papel histórico e social na mediação cultural, com reflexos sobre o fluxo de informações, sobre a construção de imagens culturais e sobre o estabelecimento de relações de convencimento entre diferentes agentes.

Nesse cenário, Kremer (2007) defende - como alternativa ao que ela denomina como ética da igualdade - uma ética pós-moderna, que promova a visibilidade de tradutores(as) e permita aos(às) leitores(as) avaliar a coerência entre a proposta construída na política tradutória e a forma que o texto traduzido efetivamente assume. Segundo Kremer (2007, p.4011-2)

\begin{abstract}
É preciso ampliar os saberes éticos da tradução e rever a ética tradicional com base na ética proposta pelos estudos pó[s]-modernos da tradução. Uma ética relacionada com a visibilidade, com a coerência do que se diz com o que se faz, com a responsabilidade do tradutor, cujo comprometimento se dará a partir do momento em que se assumir como produtor de significados e não como mero transportador. Esse comprometimento ético e político pode ser viabilizado quando o caráter indiscutivelmente intervencionista da tradução for explicitado por meio de prefácios do tradutor e reconhecido por teóricos e leitores. O não apagamento do tradutor, passa a ser, nesse contexto, uma maneira de torná-lo responsável e comprometido com o saber ético pós-moderno. Um saber ético sem normas prescritas, mas normas inscritas em cada situação, em cada jogo de linguagem, em cada projeto de tradução.
\end{abstract}

Ao convidar tradutores(as) a explicitarem seus saberes éticos, Kremer (2007) mostra uma preocupação em garantir que o público-alvo das traduções possa ter meios para saber as visões e posturas subjacentes à construção dos textos traduzidos a que tem acesso. Tratase de uma posição que encontra amparo em autores como, por exemplo, Antoine Berman (1995) e Sherry Simon (1996).

Berman (1995) defende que todas as possibilidades de tradução são válidas, desde que o processo decisório por trás delas seja franco/aberto, e enfatiza que todas traduções significativas são baseadas em projetos de tradução, por ele definidos como objetivos articulados, que envolvem desde a posição do(a) tradutor(a) até as demandas e características específicas do texto a ser traduzido. Esses projetos seriam, portanto, o princípio norteador por trás de todo o processo decisório de uma tradução, constituindo o sistema subjacente a todas as escolhas realizadas na construção de um texto-alvo. Simon (1996, p.35), também amparada em Berman (1995), ressalta a necessidade de reconhecer "o projeto tradutório como uma influência formativa sobre o texto final", defendendo que tradutores e tradutoras construam suas posições, sem se basear em ideias prédeterminadas, mas com foco nas questões efetivamente trabalhadas em cada situação de tradução. Infelizmente, a morte prematura de Antoine Berman - em 1991, aos 48 anos não nos possibilitou que o autor desenvolvesse mais trabalhos sobre como percebia as possibilidades para a efetiva promoção dessa ética da diferença, como bem ressalta Venuti 
(1998).

Um ponto importante a ser considerado a partir das discussões de Kremer (2007), Berman (1995) e Simon (1996) é não haver normas prescritas para a construção de um projeto de tradução. Trata-se de algo a ser construído a partir das características individuais de cada tarefa de tradução, analisada dentro de seu contexto específico, pois, como explica Berman (2002), citado por Sousa et al (2011, p.84), "todo texto a ser traduzido apresenta uma sistematicidade própria que o movimento de tradução encontra, enfrenta e revela".

Outro ponto importante, que também reitera a impossibilidade de se poder pressupor que haja traduções que possam ser consideradas definitivas pode ser associado ao fato de que, como aponta Bassnett (1980, p.105), até mesmo um(a) único(a) tradutor(a) pode

produzir diversas 'novas' versões de um dado texto, não com o objetivo de chegar a uma 'tradução perfeita', mas porque cada versão [...] representa uma leitura [do texto fonte], acessível no momento em que é produzida.

Assim, entendendo que não há projetos de tradução que possam ser considerados universalmente corretos para quaisquer casos e que um mesmo projeto de tradução pode ser alterado quando colocado em um contexto diferente, defende-se aqui uma postura acerca de ética semelhante à de Singer (2011). Promove-se, portanto, uma ética da tradução que se constitua como uma prática social que estimula a reflexão ativa sobre as traduções, analisadas em função de projetos de tradução (ou das linhas de raciocínio construídas por trás das decisões de tradução) que venham a ser publicados em conjunto com os textos traduzidos.

Trata-se de uma perspectiva sobre a ética da tradução que pode permitir, pelo lado do(a) analista, acesso a indícios sobre os esquemas individuais de percepção da realidade de cada tradutor(a) - utilizando aqui os termos de Fludernik (1996) - , podendo até mesmo permitir a discussão acerca dos mecanismos de interpretação de cada leitor(a)/tradutor(a). Já pelo lado do(a) consumidor(a) do texto-alvo, essa mudança pode permitir uma localização mais clara dos textos-alvo nos seus contextos de recepção, com implicações até mesmo para a percepção dos trabalhos de tradutores(as) enquanto produtores(as) de conhecimento.

O fato de se tratar de uma postura que não prescreve modelos para a construção de projetos de tradução não deve, no entanto, ser visto como um fator impeditivo ou desestimulador do debate sobre o tema. Pelo contrário, é importante que o campo disciplinar aproveite essa abertura para desenvolver discussões que estimulem a reflexão sobre as práticas de tradução, visando a entender os raciocínios desenvolvidos para a construção de textos-alvo.

Outro ponto de igual importância é a discussão sobre como tornar tais projetos públicos e como ampliar o debate em torno desses projetos, reconhecendo as diferentes possibilidades leitura abertas por um texto-fonte e analisando as diferentes possibilidades de tradução em função das discussões explicitadas por tradutores(as) em torno dos valores 
subjacentes às suas decisões de tradução e as limitações que eles(as) percebem em relação aos seus trabalhos.

Dentre os trabalhos que podem indicar caminhos nesse sentido, podem ser feitas algumas indicações. Simon (1996, p.35), por exemplo, destaca tradutoras feministas como "Barbara Godard, Suzanne Jill Levine, Susanne de Lotbinière-Harwood ou Luise von Flotow, em suas formas personalizadas de escrita crítica". Trata-se, segundo a autora, de trabalhos que desenvolvem uma postura ética ao apresentar as posições subjacentes às suas traduções.

Outra indicação de meios para explicitar os projetos tradutórios ou princípios que guiam tarefas de tradução é dada por Venuti $(1995$, p.311) que, ao defender uma maior visibilidade dos trabalhos de tradutores e tradutoras por meio do desenvolvimento de práticas inovadoras de tradução (que fujam à norma do apagamento e da invisibilidade), sugere a apresentação de "discussões lógicas sofisticadas para essas práticas em prefácios, teses, palestras, entrevistas".

Por fim, Alves, Braga e Liparini (2016) também se colocam neste debate, discutindo os processos decisórios por trás da construção de um texto-alvo, que, segundo os autores, tem pressupostos ideológicos controversos. Os autores citam Baker $(2014$, p.23) para argumentar que, ao abrir, para a comunidade acadêmica, o debate sobre tais processos decisórios, criam-se as condições para uma maior compreensão sobre os "papéis que tradutores(as) e intérpretes desempenham em suprimir ou promover aspectos relativos às experiências vividas por grupos marginalizados". Além disso, como apontam os autores, discutir o processo decisório por trás da construção de um texto traduzido é também uma forma de trazer, para o público acadêmico, uma visão interna da tradução, que a enxerga como "uma atividade humana complexa e nuançada, influenciada por uma miríade de forças internas e externas" (ALVES, BRAGA e LIPARINI, 2016, p.405).

\section{Considerações finais}

Este texto buscou construir uma discussão acerca de ética dentro de um contexto dos Estudos da Tradução, ancorando-se em Singer (2011) - ao entender ética uma como prática social que promove a reflexão consciente sobre os comportamentos do indivíduo em relação ao seu grupo social e às expectativas desse grupo. Central para essa visão é a construção explícita de políticas tradutórias - entendidas como racionalizações, produzidas pelos(as) tradutores(as), refletindo sobre os sistemas de escolha subjacentes a cada tarefa de tradução, com reflexões acerca das suas percepções sobre o texto-fonte, sobre seus locais de fala e sobre as limitações que eles(as) percebem ao produzir o texto-alvo em questão. A visão promovida neste texto se baseia em discussões sobre o reconhecimento do papel ativo que os(as) tradutores(as) assumem no processo de comunicação que é possibilitado por cada texto traduzido e reconhece a multiplicidade de possíveis leituras para um mesmo textofonte e a consequente multiplicidade de possíveis escolhas tradutórias. 
Reconhecem-se aqui, os limites desta discussão para contextos acadêmicos - não tão sujeitos às limitações e diretrizes prévias comumente impostas para trabalhos de tradução comerciais. Para um contexto não sujeito a tais limitações, a produção explícita de políticas tradutórias (bem como sua publicação, acompanhando as traduções a elas relacionadas) poderia levara uma mudança de paradigma, na qual o(a) tradutor(a) deixa de ser invisível e sua ação política sobre o texto passa a ser reconhecida, levando em conta as suas interpretações e as limitações colocadas ao seu trabalho. Promove-se, portanto usando as palavras de Kremer (2007, p.4012) - "[u]m saber ético sem normas prescritas, mas normas inscritas em cada situação, em cada jogo de linguagem, em cada projeto de tradução".

No começo deste texto, é feita uma menção à descrição de Singer (2011) quanto ao fato de o tema ética ser abrangente, ramificado e com várias implicações filosóficas, dependendo das vertentes teóricas trabalhadas. Neste texto, foi tomada uma decisão consciente em trabalhar uma visão acerca do tema, ancorada em Singer (2011) e em teóricos(as) afiliados(as) aos Estudos da Tradução - como Berman (1995), Simon (1996) e Kremer (2007) - cujas posições se mostram compatíveis com a definição de ética aqui trabalhada. É necessário reconhecer que essa delimitação não implica desmerecimento em relação a outras posições acerca do tema ética nos Estudos da Tradução.

Encerro esta discussão mencionando, portanto, outras discussões possíveis sobre ética no âmbito dos Estudos da Tradução (para além das visões deônticas). Com isso, buscase aqui não apenas reconhecer, mas também incentivar o debate a partir de outros ângulos. Pym (2012) revisita discussões sobre a ética do(a) tradutor(a) e da tradução, abordando questões históricas, revisitando autores e discussões clássicas - de Schleiermacher a discussões sobre a tradução de textos religiosos, passando pela discussão de binarismos e pela posição do(a) tradutor(a) como mediador(a) cultural. Pym (2012, p. 165-7) propõe alguns princípios para a construção de uma ética do(a) tradutor(a), baseando-se em uma visão da ética como forma de justiça, dentre eles: a) da responsabilidade do(a) tradutor(a) sobre o material que produz; b) da responsabilidade do(a) tradutor(a) sobre os efeitos gerados pelo material que produz; c) de não ter que aderir a dualismos que impliquem o favorecimento de uma cultura em detrimento de outra e de poder se colocar como agente promotor(a) da cooperação entre culturas); d) dos custos das transações; e) de se colocarem como agentes da cooperação entre culturas. Mais recentemente, em um seminário online intitulado Translator Ethics: From Cooperation to Risk and Trust $^{8}$, realizado em (24 de setembro de 2020), Pym voltou a abordar a questão da ética da tradução, mas com foco na ideia de cooperação e no papel do(a) tradutor(a) perante os seus pares (enfatizando a ética em relação à profissão em si).

Alwazna (2014) revê conceitos tradicionalmente trabalhados nos Estudos da Tradução, propondo que o campo disciplinar ultrapasse a ideia simplista de ética na tradução apenas significar a produção, na língua-alvo, de um texto que mantenha os significados do

\footnotetext{
${ }^{8}$ Disponível em https://ctn.hkbu.edu.hk/event/translator-ethics-from-cooperation-to-risk-and-trust/ - último acesso em 17 de novembro de 2020.
} 
texto-fonte. $\mathrm{O}$ autor defende que o conceito de ética seja visto de forma mais abrangente, compreendendo as relações com os contextos de consumo dos textos traduzidos e com as suas audiências esperadas. Alwazna (2014) aborda questões relativas a normas e a diferentes expectativas acadêmicas quanto às funções sociais da tradução, discutindo o contínuo entre aderir à forma e ao conteúdo do texto-fonte e a exploração de formas mais associáveis ao contexto do texto-alvo.

Drugan e Tipton (2017) se concentram sobre a questão da responsabilidade social de intérpretes e tradutores(as) em situações de comunicação intercultural, entre línguas e entre culturas. As autoras enfatizam questões sociais que afetam as partes interessadas em traduções - incluindo tradutores(as) e intérpretes, clientes e usuários(as) de textos traduzidos - e abordam questões associadas a formação de tradutores(as), ao espaço para preparação e/ou oportunidade de reflexão sobre estratégias para lidar com problemas de tradução.

Por fim, Hunt et al (2019) aborda a questão da tradução em contextos de crise humanitária e o papel ético do(a) tradutor(a) em promover o acesso à informação como direito humano. Promovendo uma discussão a partir de um estudo de caso sobre o atendimento às vítimas do terremoto que atingiu o Haiti em 2010, Hunt et al (2019) discute a implementação de recursos tecnológicos (como mensagens eletrônicas e mapas interativos, por exemplo) em respostas humanitárias e o estabelecimento de diretrizes de comunicação para o envio de informações traduzidas para orientar a população afetada por tragédias. Nesse contexto, o trabalho destaca a importância da comunicação multilíngue da superação de barreiras no salvamento de vidas.

\section{Referências}

ALVES, Daniel; BRAGA, Camila; LIPARINI, Tânia Translation and Ethics: making translation choices ideologies that underlie the source text. Letras \& Letras, v. 32, n. 1, p. 403-419, 21 ago. 2016. DOI: https://doi.org/10.14393/LL63-v32n1a2016-21

ALWAZNA, Rafat. Ethical Aspects of Translation: Striking a Balance between Following Translation Ethics and Producing a TT for Serving a Specific Purpose. English Linguistics Research. Volume 3, №1, 2014. DOI: 10.5430/elr.v3n1p51.

BAKER, Mona. The Changing Landscape of Translation and Interpreting Studies. In: BERMANN, Sandra \& PORTER, Catherine. A Companion to Translation Studies. John Wiley \& Sons, Ltd, Oxford, UK, 2014, p. 15-27. http://dx.doi.org/10.1002/9781118613504.ch1

BERMAN, Antoine. Pour une critique des traductions: John Donne, Paris: Gallimard. 1995.

BASSNETT, Susan. Translation Studies. London and New York: Routledge, 1980.

COSTA VAL, Maria da Graça. Texto, textualidade e textualização. CECCANTINI, J.L. Tápias; PEREIRA, Rony F.; ZANCHETTA JR., Juvenal. Pedagogia Cidadã: cadernos de formação: Língua Portuguesa. v. 1. São Paulo: UNESP, Pró-Reitoria de Graduação, 2004. p. 113-128.

DRUGAN, Joanna e TIPTON, Rebecca. Translation, ethics and social responsibility. The Translator, Volume 23:2, 2017. pp.119-125, DOI: 10.1080/13556509.2017.1327008 
FLUDERNIK, Monika. Towards a 'Natural' Narratology. London and New York: Routledge, 1996.

KREMER, Lucia Maria Silva. Desvendando saberes: o caso da tradução de "Dom Casmurro" para o inglês. In: VII Congresso Nacional de Educação - EDUCERE. Anais, Paraná, Novembro de 2007, p. 4003-14.

NIETZSCHE, Friedrich. The Will to Power. New York: Vintage Books, 1901 (1968).

PYM, Anthony. On Translator Ethics: Principles of mediation between cultures. Amsterdam / Philadelphia: John Benjamins Publishing Company, 2012

SIMON, Sherry. Gender in Translation: Cultural identity and the politics of transmission. London and New York: Routledge, 1996.

SINGER, Peter. Practical Ethics. Cambridge, New York, Melbourne, Madrid, Cape Town, Singapore, Sao Paulo, Delhi, Dubai, Tokyo, Mexico City: Cambridge University Press, 2011 (1a ed 1980).

SOUSA, Germana et al. Escritores tradutores brasileiros e a tradução dos nomes próprios. Translationes, Volume 3, 2011. DOI: 10.2478/tran-2014-0048

VENUTI, Lawrence. The Translator's Invisibility. London and New York: Routledge, 1995.

VENUTI, Lawrence. The Scandals of Translation: Towards an Ethics of Difference. London and New York: Routledge, 1998.

Recebido em: 10/10/2020.

Aceito em: 15/11/2020. 